\title{
Hydrogen sulfide suppresses transforming growth factor- $\beta 1$-induced differentiation of human cardiac fibroblasts into myofibroblasts
}

\author{
ZHANG YouEn ${ }^{1,2}$, WANG JiaNing ${ }^{1}$, LI Hua ${ }^{2,3}$, YUAN LiangJun $^{1}$, WANG Lei ${ }^{1}$, WU Bing ${ }^{1}$ \\ \& GE JunBo ${ }^{2,3 *}$ \\ ${ }^{1}$ Institute of Clinical Medicine and Department of Cardiology, Renmin Hospital, Hubei University of Medicine, Shiyan 442000, China; \\ ${ }^{2}$ Shanghai Institute of Cardiovascular Diseases, Zhongshan Hospital, Fudan University, Shanghai 200032, China; \\ ${ }^{3}$ Institutes of Biomedical Sciences, Fudan University, Shanghai 200032, China
}

Received May 2, 2015; accepted May 6, 2015; published online August 4, 2015

\begin{abstract}
In heart disease, transforming growth factor- $\beta 1$ (TGF- $\beta 1$ ) converts fibroblasts into myofibroblasts, which synthesize and secrete fibrillar type I and III collagens. The purpose of the present study was to investigate how hydrogen sulfide $\left(\mathrm{H}_{2} \mathrm{~S}\right)$ suppresses TGF- $\beta 1$-induced differentiation of human cardiac fibroblasts to myofibroblasts. Human cardiac fibroblasts were serum-starved in fibroblast medium for $16 \mathrm{~h}$ before exposure to TGF- $\beta 1\left(10 \mathrm{ng} \mathrm{mL}^{-1}\right)$ for $24 \mathrm{~h}$ with or without sodium hydrosulfide (NaHS, $100 \mu \mathrm{mol} \mathrm{L}{ }^{-1}, 30$ min pretreatment) treatment. NaHS, an exogenous $\mathrm{H}_{2} \mathrm{~S}$ donor, potently inhibited the proliferation and migration of TGF- $\beta 1$-induced human cardiac fibroblasts and regulated their cell cycle progression. Furthermore, NaHS treatment led to suppression of fibroblast differentiation into myofibroblasts, and reduced the levels of collagen, TGF- $\beta 1$, and activated Smad3 in TGF- $\beta 1$-induced human cardiac fibroblasts in vitro. We therefore conclude that $\mathrm{H}_{2} \mathrm{~S}$ suppresses TGF- $\beta 1$-stimulated conversion of fibroblasts to myofibroblasts by inhibiting the TGF- $\beta 1 / \mathrm{Smad} 3$ signaling pathway, as well as by inhibiting the proliferation, migration, and cell cycle progression of human cardiac myofibroblasts. These effects of $\mathrm{H}_{2} \mathrm{~S}$ may play significant roles in cardiac remodeling associated with heart failure.
\end{abstract}

human cardiac fibroblasts, hydrogen sulfide, transforming growth factor $\beta 1$, myofibroblasts

Citation: Zhang YE, Wang JN, Li H, Yuan LJ, Wang L, Wu B, Ge JB. Hydrogen sulfide suppresses transforming growth factor- $\beta 1$-induced differentiation of human cardiac fibroblasts into myofibroblasts. Sci China Life Sci, 2015, 58: 1126-1134, doi: 10.1007/s11427-015-4904-6

Cardiac fibroblasts (CFs) are the most common cell type in the adult myocardium, accounting for about two-thirds of the cell population. They are embedded within the extracellular matrix (ECM) of the connective tissue and are, to a large extent, responsible for its synthesis and degradation [1]. However, CFs have received relatively little attention compared to their more famous neighbors, the cardiomyocytes. Emerging studies reveal that fibroblasts are fundamentally involved in cardiac remodeling in normal ageing heart and

*Corresponding author (email: ge.junbo@zs-hospital.sh.cn) in damaged myocardium [2,3]. Other recent studies have suggested a "sentinel" role for CFs that is intimately associated with myocardial response to a broad range of stimuli during cardiac development and disease, including hypoxia, and changes in chemical, electrical, and mechanical signals. Due to their potential role in the regulation of global myocardial function, fibroblasts have become a promising therapeutic target in heart disease.

Hydrogen sulfide $\left(\mathrm{H}_{2} \mathrm{~S}\right)$ was previously regarded as a toxic gas. However, recent evidence suggests that $\mathrm{H}_{2} \mathrm{~S}$ is an emerging endogenous gasotransmitter in mammals that 
promotes vasorelaxation, cardioprotection, neurotransmission, and anti-inflammatory action in the gastrointestinal tract $[4,5]$. These findings, which indicate that $\mathrm{H}_{2} \mathrm{~S}$ is an endogenous signaling molecule (second messenger) capable of modulating various physiological processes including vasodilation, and that it parallels the action of nitric oxide (NO), prompted us to investigate the potential of $\mathrm{H}_{2} \mathrm{~S}$ as a cardioprotective agent $[6,7]$. We recently reported that transplantation of exogenous $\mathrm{H}_{2} \mathrm{~S}$-pretreated mesenchymal stem cells (MSCs) could reduce infarct size and increase left ventricular function in a rat myocardial infarction model [8]. However, little is known about the mechanism(s) by which $\mathrm{H}_{2} \mathrm{~S}$ affects cell growth and function. Therefore, in the present study, we tested the hypothesis that direct administration of the $\mathrm{H}_{2} \mathrm{~S}$ donor-sodium hydrosulfide (NaHS) affects the proliferation, migration, and differentiation of transforming growth factor- $\beta 1$ (TGF- $\beta 1$ )-induced CFs into myofibroblasts in vitro.

\section{Materials and methods}

\subsection{Cell Culture}

Human Cardiac Fibroblasts-adult ventrical cells (HCF-av, Catalog\# 6310) were obtained from ScienCell Research Laboratories (San Diego, USA) and cultured in fibroblast media (FM) supplemented with $2 \%$ fetal bovine serum, $1 \%$ fibroblast growth supplement (FGS), and $1 \%$ penicillin/streptomycin solution (P/S) according to the manufacturer's protocol (ScienCell Research Laboratories). Cells were subcultured when they became more than $90 \%$ confluent. Cells at passage 3 to 6 were used for experiments [9].

\subsection{Experimental design}

HCF-av cells were serum-starved in FM for $16 \mathrm{~h}$ prior to experiments. Cells were then stimulated with TGF- $\beta 1$ (10 $\mathrm{ng} \mathrm{mL} \mathrm{m}^{-1}$, Sigma, USA) for $24 \mathrm{~h}$ to promote the cardiac myofibroblast phenotype $[9,10]$ in the absence or presence of NaHS (100 $\mathrm{mol}^{-1}, 30 \mathrm{~min}$ pretreatment; Sigma).

\subsection{Cell proliferation assay}

Cell proliferation was determined by Bromodeoxyuridine (BrdU) incorporation using a colorimetric kit from Roche Applied Science, according to the manufacturer's instructions. Briefly, $5 \times 10^{3}$ cells per well were seeded on flat-bottom 96-well plates. Cells were then starved in serum-free media for $16 \mathrm{~h}$. Proliferation was induced by culturing cells in TGF- $\beta 1$ in the absence or presence of NaHS. Cells were then exposed to the BrdU labeling solution (10 $\mu \mathrm{mol}^{-1}$ ), fixed, and incubated with an anti-BrdU-POD (peroxidase) working solution, followed by a detection sub- strate. Emission at $450 \mathrm{~nm}$ was immediately measured on a standard enzyme-linked immunosorbent assay (ELISA) plate reader (Infinite 200, TECAN).

\subsection{Cell migration assay}

The migration of HCF-av cells was determined using a wound-healing assay, as previously described [11]. Briefly, confluent cultured HCF-av cells were grown in 6-well plates. After the cells were serum-starved in FM media for $16 \mathrm{~h}$, they were scratched with a sterile $1 \mathrm{~mL}$ pipette tip and then washed twice with phosphate buffered saline (PBS) to remove unattached cells. The cells were then cultured in FM supplemented with TGF- $\beta 1\left(10 \mathrm{ng} \mathrm{mL}^{-1}\right)$ in the absence or presence of NaHS $\left(100 \mu \mathrm{mol} \mathrm{L}{ }^{-1}\right)$. To standardize the position of the wound for imaging, small indentations were made at the bottom of the plate. Cell migration was determined after $24 \mathrm{~h}$ by counting cells that had moved out of the initial area.

\subsection{Measurement of cell cycle distribution}

Exponentially growing HCF-av cells cultured in T-25 flasks were either treated with TGF- $\beta 1\left(10 \mathrm{ng} \mathrm{mL}^{-1}\right)$ or left untreated, in the absence or presence of NaHS $\left(100 \mu \mathrm{mol} \mathrm{L}^{-1}\right)$. $24 \mathrm{~h}$ after treatment, the cells were harvested by trypsinization, washed twice in PBS, and fixed in ice-cold ethanol $(70 \%, v / v)$ overnight at $4^{\circ} \mathrm{C}$. Cells were stained with propidium iodide (PI, $50 \mu \mathrm{g} \mathrm{L}^{-1}$; Sigma) for $30 \mathrm{~min}$ in the

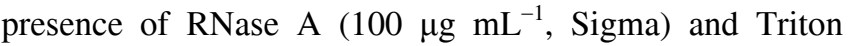
$\mathrm{X}-100(0.1 \%, \mathrm{v} / \mathrm{v})$. The cell cycle distribution of HCF-av cells was determined by flow cytometry (FACS Calibur, BD Biosciences, USA). Flow cytometry data were acquired using CellQuest software (10,000 cells were recorded for each sample), and the cell profile was assessed using ModFit software.

\subsection{Apoptosis assay}

An Annexin V apoptosis detection kit (BD Biosciences) was used to measure apoptosis of HCF-av cells by following the manufacturer's instructions. Briefly, after treatment, cells were washed twice with cold PBS and then resuspend in $1 \times$ binding buffer at a concentration of $1 \times 10^{6}$ cells $\mathrm{mL}^{-1}$. A $100 \mu \mathrm{L}$ aliquot of this cell solution $\left(1 \times 10^{5}\right.$ cells $)$ was transferred to a $5 \mathrm{~mL}$ culture tube and incubated with fluorescein isothiocyanate (FITC)-Annexin V $(5 \mu \mathrm{L})$ and PI $(5 \mu \mathrm{L})$ for $15 \mathrm{~min}$ at $\mathrm{RT}$ in the dark. The cells were then analyzed by flow cytometry within $1 \mathrm{~h}$ of staining.

\subsection{Immunocytochemistry}

Immunocytochemistry was performed as previously described [12]. Cells plated on chamber slides were fixed in 
4\% paraformaldehyde for $15 \mathrm{~min}$ at room temperature, permeabilized with Triton X-100, and blocked with albumin from bovine serum (BSA). The cells were then incubated with a primary antibody against $\alpha$-smooth muscle actin ( $\alpha$-SMA, Sigma) overnight at $4^{\circ} \mathrm{C}$ and subsequently washed with PBS three times, followed by incubation with a FITC-conjugated secondary antibody (Jackson Immunoresearch) for $1 \mathrm{~h}$ at room temperature. After washing with PBS, cells were incubated with 4',6-diamidino-2phenylindole dihydrochloride (DAPI) and analyzed by fluorescent microscopy. Cells were counted and scored from five randomly selected areas of each slide, and quantitative analysis was performed using Image-Pro Plus software.

\subsection{Western blot analysis}

Western blot analysis was performed as previously described [13]. Cells were washed twice with PBS and harvested in radio immune precipitation assay (RIPA) buffer containing a protease inhibitor cocktail (Thermo Scientific) and phenylmethanesulfonyl fluoride (PMSF; $1 \mathrm{mmol} \mathrm{L}^{-1}$ ). Equal amounts $(30 \mu \mathrm{g})$ of samples were separated by sodium dodecyl sulfate-polyacrylamide gel electrophoresis (SDS-PAGE) and then transferred to polyvinylidene difluoride membranes (PVDF, Millipore, USA) using a Trans-blot apparatus (Bio-Rad, USA). Membranes were blocked with 5\% BSA in Tris-buffered saline containing $0.1 \%$ Tween-20 (TBST) for $1 \mathrm{~h}$ at RT and were subsequently incubated with anti- $\alpha$-SMA (Sigma; 1:1000 dilution), anti-Collagen I (ABcam; 1:5000 dilution), anti-Collagen III (ABcam; $1: 5000$ dilution), anti-TGF- $\beta 1$ (ABcam; 1:800 dilution), and anti-phospho-Smad3 (CST; 1:1000 dilution) primary antibodies overnight at $4{ }^{\circ} \mathrm{C}$. Blots were washed with TBST, followed by incubation with corresponding horseradish peroxidase (HRP)-conjugated secondary antibodies (Jackson Immunoresearch). Protein signals were detected using enhanced chemiluminescence reagents and were quantified by densitometry.

\subsection{Statistics analysis}

Data are expressed as $\bar{x} \pm \mathrm{SE}$. Different groups were compared by one-way ANOVA followed by the StudentNewman-Keuls post-hoc test. Comparison between two groups was assessed by a Student's $t$ test, and a $P<0.05$ indicated statisitcal significance.

\section{Results}

\section{1 $\mathrm{H}_{2} \mathrm{~S}$ inhibits TGF- $\beta$ 1-induced proliferation of HCF-av cells}

To determine the effect of NaHS on the proliferation of
$\mathrm{HCF}$, cells were stimulated with TGF- $\beta 1$ followed by BrdU labeling. Cell proliferation of TGF- $\beta 1$ stimulated cells was substantially increased as indicated by the increase in BrdU-positive cells, compared to the control. However, NaHS treatment dramatically reduced cell proliferation (Figure 1).

\section{2 $\mathrm{H}_{2} \mathrm{~S}$ antagonizes TGF- $\beta 1$-induced migration of $\mathrm{HCF}$-av cells}

To investigate whether $\mathrm{H}_{2} \mathrm{~S}$ inhibits migration of $\mathrm{HCF}-\mathrm{av}$ cells, we performed a wound-healing assay. Cells in culture were scraped with a $1,000 \mu \mathrm{L}$ pipette tip and a wide acellular area was produced. Figure 2A illustrates that the wound was completely closed in HCF-av cells treated with $10 \mathrm{ng} \mathrm{mL}^{-1}$ TGF- $\beta 1$ for $24 \mathrm{~h}$. The number of CFs migrating into

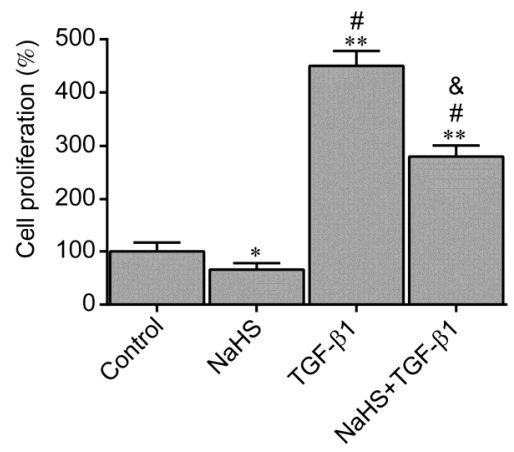

Figure $1 \mathrm{H}_{2} \mathrm{~S}$ inhibits TGF- $\beta 1$-induced proliferation of HCF-av cells. Proliferation of cells with or without TGF- $\beta 1\left(10 \mathrm{ng} \mathrm{mL}^{-1}\right)$ treatment, and in the absence or presence of NaHS $\left(100 \mu \mathrm{mol} \mathrm{L}^{-1}\right)$. $*, P<0.05 ; * *, P<0.01$ vs. Control; \#, $P<0.01$ vs. NaHS; $\&, P<0.01$ vs. TGF- $\beta 1(n=6)$.

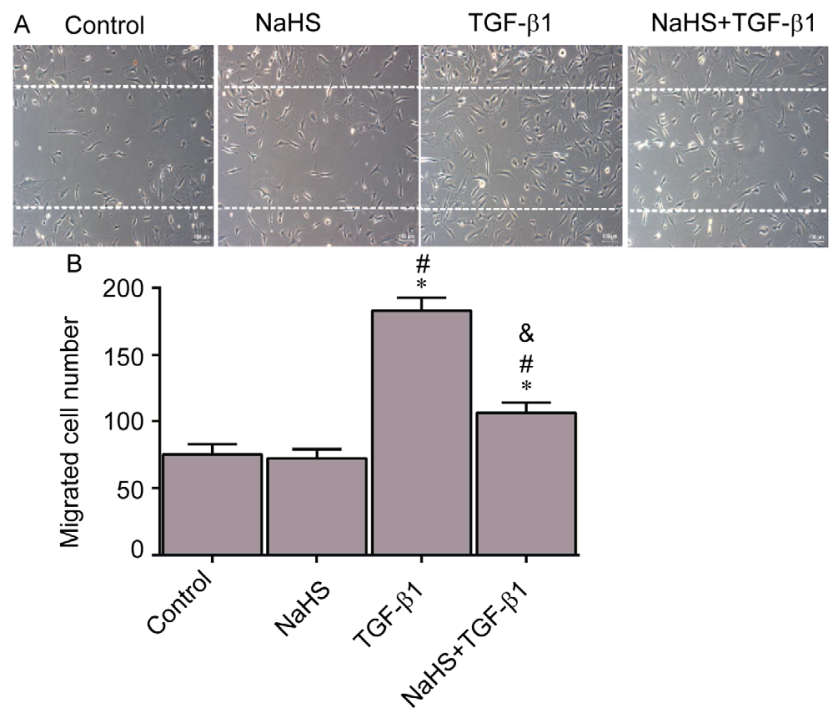

Figure $2 \mathrm{H}_{2} \mathrm{~S}$ antagonizes TGF- $\beta 1$-induced migration of $\mathrm{HCF}-\mathrm{av}$ cells. A, Wound-healing migration assay on HCF-av cells. Broken white lines indicate the initial acellular wound regions. B, Mean values for the number of migrated HCF-av cells counted in the areas defined in A. *, $P<0.01$ vs. Control; \#, $P<0.01$ vs. NaHS; $\&, P<0.01$ vs. TGF- $\beta 1$ ( $n=6)$. 
the acellular area was calculated and expressed as the number of migrated cells (Figure 2B). Similarly, a substantial number of cells populated the scratched area. However, $\mathrm{H}_{2} \mathrm{~S}$ markedly antagonized TGF- $\beta 1$-induced migration.

\subsection{Role of $\mathrm{H}_{2} \mathrm{~S}$ in cell cycle distribution}

Subconfluent cycling HCF-av cells were stimulated with TGF- $\beta 1$ in the absence or presence of NaHS and collected $24 \mathrm{~h}$ after treatment. The percentage of cells in each cell cycle phase $\left(\mathrm{G}_{0} / \mathrm{G}_{1}, \mathrm{~S}\right.$, and $\left.\mathrm{G}_{2} / \mathrm{M}\right)$ was determined by flow cytometry (Figure 3A). Figure 3B demonstrates that there was no significant difference in the number of cells in the $\mathrm{G}_{0} / \mathrm{G}_{1}$ phase in all treatment groups compared to the control. However, exposure to TGF- $\beta 1$ increased the percentage of $\mathrm{S}$ phase cells, but NaHS blocked this increase (Figure 3C). $\mathrm{NaHS}$ and/or TGF- $\beta 1$ treatment resulted in a higher number cells in the $\mathrm{G}_{2} / \mathrm{M}$ phase compared to the control (Figure 3D).

\subsection{Apoptosis}

We evaluated whether NaHS or TGF- $\beta 1$ could induce apoptosis in HCF-av cells. However, there was no significant difference in the number of apoptotic cells (Annexin $\mathrm{V}^{+} \mathrm{PI}^{+}$) between all experimental groups, indicating that nei- ther TGF- $\beta 1$ nor NaHS could induce apoptosis in HCF-av cells (Figure 4A, B).

\section{5 $\quad \mathrm{H}_{2} \mathrm{~S}$ suppresses TGF- $\beta 1$-induced differentiation of HCF-av cells to myofibroblasts}

TGF- $\beta 1$ is the most potent stimulor of fibroblast differentiation to myofibroblasts that express $\alpha$-SMA microfilaments, which confer contractile behavior to myofibroblasts. As shown in Figure 5A and 5B, TGF- $\beta 1$ upregulated $\alpha$-SMA expression $3.9 \pm 0.8$ fold, compared to the control $(P<0.01)$. Furthermore, the addition of NaHS potently abrogated $\alpha$-SMA expression induced by TGF- $\beta 1$. This effect was confirmed by immunocytochemical analysis of $\alpha$-SMA protein expression, which showed that $24 \mathrm{~h}$ TGF- $\beta 1$ exposure potently increased the expression and organization of $\alpha$-SMA microfilaments and led to larger cells, which is consistent with the myofibroblast phenotype (Figure 5C). However, TGF- $\beta 1$-induced myofibroblast differentiation was abrogated by NaHS (Figure 5D).

\section{6 $\mathrm{H}_{2} \mathrm{~S}$ blocks TGF- $\beta 1$-induced Collagen I and Colla- gen III expression in HCF-av cells}

Collagen protein expression in response to TGF- $\beta 1$ or $\mathrm{H}_{2} \mathrm{~S}$ stimulation was assessed by western blotting (Figure 6A).

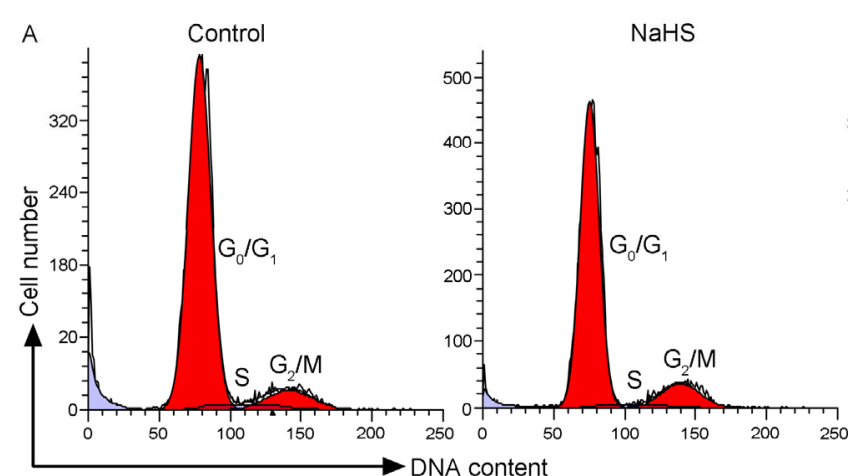

B

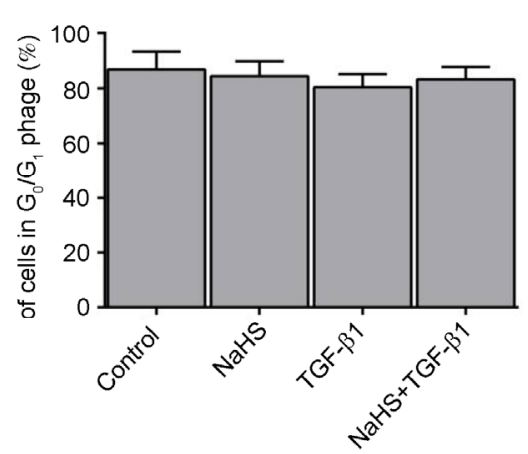

C

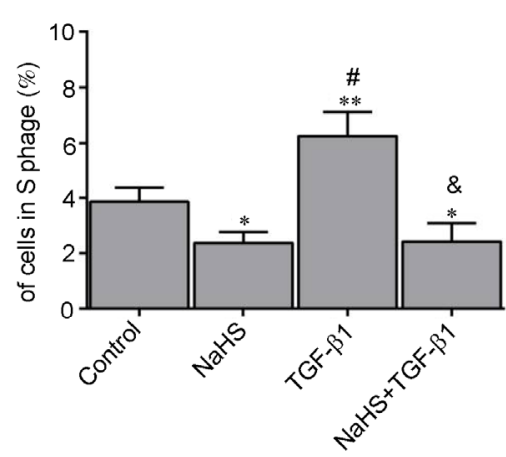

D

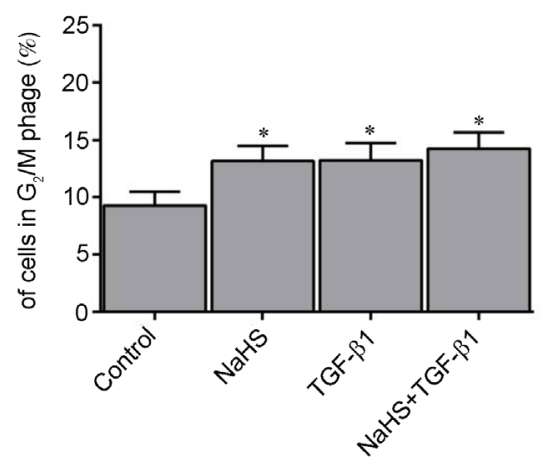

Figure 3 Effect of $\mathrm{H}_{2} \mathrm{~S}$ on cell cycle progression in TGF- $\beta 1$-induced HCF-av cells. A, Representative image of PI stained cells showing DNA distribution as analyzed by flow cytometry. B, Quantitative comparison of the fraction of HCF-av cells in $\mathrm{G}_{0} / \mathrm{G}_{1}, \mathrm{~S}$, and $\mathrm{G}_{2} / \mathrm{M}$ cell cycle stages. *, $P<0.05$; **, $P<0.01$ vs. Control; \#, $P<0.01$ vs. NaHS; $\&, P<0.01$ vs. TGF- $\beta 1(n=6)$. 

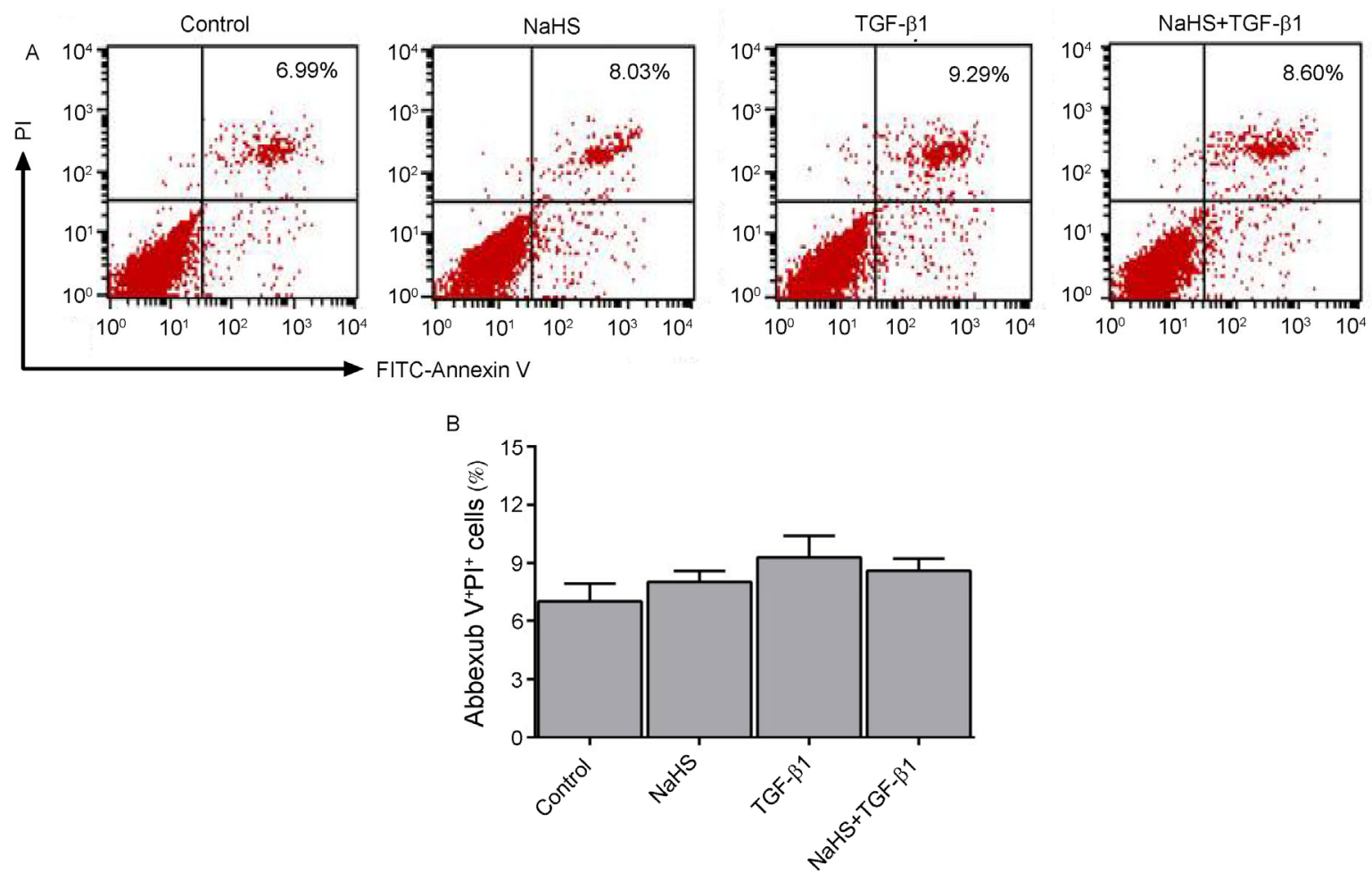

Figure 4 Exposure to TGF- $\beta 1$ with or without $\mathrm{H}_{2} \mathrm{~S}$ treatment did not induce apoptosis of HCF-av cells. A, Representative flow cytometric analysis of HCF-av apoptotic cells stained for Annexin V/PI. B, Summaries of the rate of apoptosis, represented by histograms ( $n=6)$.

We observed that TGF- $\beta 1$ treatment for $24 \mathrm{~h}$ produced more Collagen I and Collagen III than control cells, which confirmed the differentiation patterns shown in Figure 5 ( $\alpha$-SMA positive cells). $\mathrm{H}_{2} \mathrm{~S}$ significantly abrogated the TGF- $\beta 1$ induced increase in Collagen I and Collagen III.

\section{7 $\mathrm{H}_{2} \mathrm{~S}$ inhibits TGF- $\beta 1$-induced $\mathrm{Smad} 3$ activation of HCF-av cells}

To investigate the role of $\mathrm{H}_{2} \mathrm{~S}$ during TGF- $\beta 1$-induced myofibroblast differentiation, the TGF- $\beta 1$ expression was assessed by western blot. As shown in Figure 7A and 7B, cells exposed to TGF- $\beta 1$ exhibited significant increase in TGF- $\beta 1$ expression compared to the control, while NaHS treatment dramatically reduced TGF- $\beta 1$ expression.

Next, to further examine the mechanistic role of TGF- $\beta 1$, we investigated its effect on Smad3 phosphorylation. As shown in Figure $7 \mathrm{C}$ and $7 \mathrm{D}$, TGF- $\beta 1\left(10 \mathrm{ng} \mathrm{mL}{ }^{-1}\right)$ induced a robust increase in phospho-Smad3, which was dramatically reduced after NaHS treatment.

\section{Discussion}

Fibroblasts are embryologically distinct from cardiomyocytes in their origin. Following myocardial infarction they become activated, migrate to the injury site, and proliferate [14]. Interest in CFs has grown with the recognition that cardiac fibrosis is a prominent contributor to diverse forms of myocardial disease. Excessive interstitial fibrosis of failing hearts is caused by activated myofibroblasts in response to mechanical stretch, autocrine, and paracrine factors generated within the myocardium (for example, angiotensin II [Ang II] [15] and TGF- $\beta 1$ ), and circulating hormones such as aldosterone [16]. It has therefore been hypothesized that the phenotypic conversion of CFs into specialized myofibroblasts is a critical process mediating cardiac remodeling. Previous studies show that TGF- $\beta 1$ is the most potent stimulator of the activation and differentiation of fibroblasts into myofibroblasts [17]. After fibroblast maturation to myofibroblasts, an increase in the synthesis and secretion of fibronectin is observed. Therefore, in the current study, we utilized TGF- $\beta 1$ to induce myofibroblast differentiation, as this cytokine is a critical mediator of the excessive fibrogenic reaction in CF culture, animals, and humans with heart failure [9]. In cardiac remodeling, CFs exhibit various functions, including proliferation, migration, and secretion of proinflammatory cytokines and growth factors [18]. Furthermore, intense proliferative activity has been documented in fibroblasts infiltrating the infarcted heart. In the present study, TGF- $\beta 1$ induced the proliferation and migration of cultured HCF-av cells and exogenous 
A

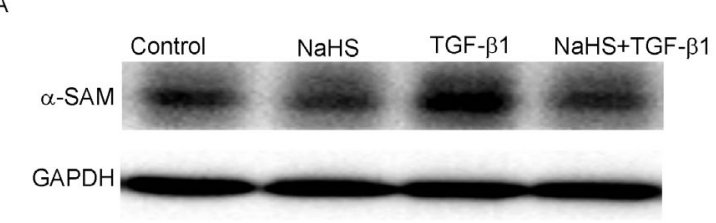

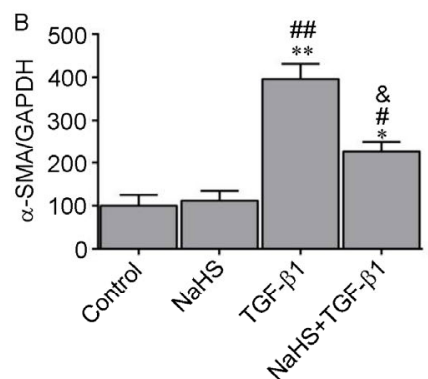

C

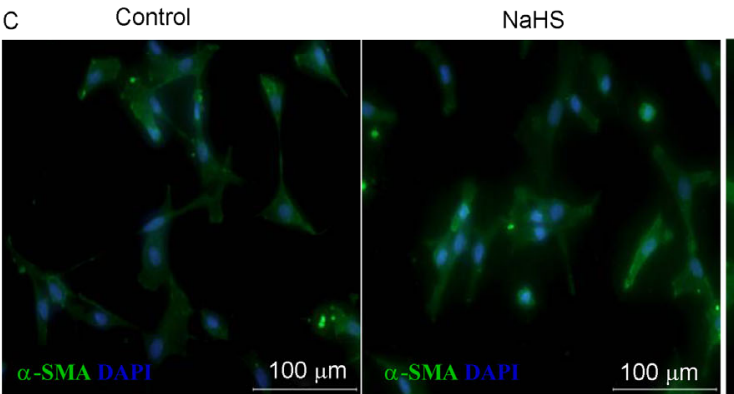

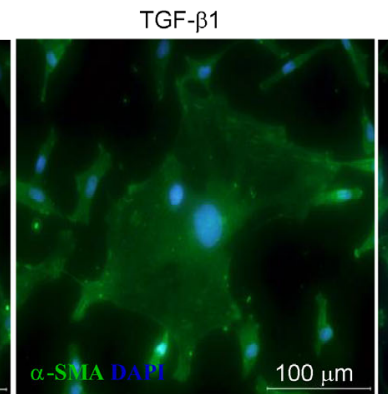

$\mathrm{NaHS}+\mathrm{TGF}-\beta 1$

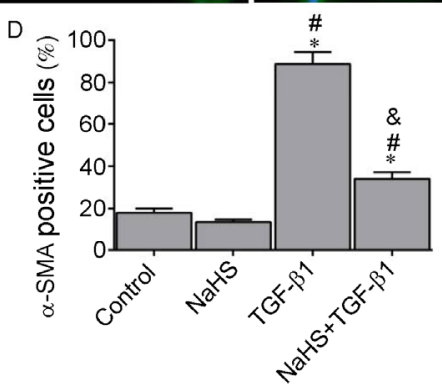

Figure $5 \mathrm{H}_{2} \mathrm{~S}$ suppresses TGF- $\beta 1$-induced differentiation of HCF-av cells into myofibroblasts. A, HCF-av cells were treated with NaHS (100 $\mu$ mol $\mathrm{L}^{-1}$ ), exposed to TGF- $\beta 1\left(10 \mathrm{ng} \mathrm{mL}^{-1}\right)$ for $24 \mathrm{~h}$, harvested, and then proteins were extracted. Western blot analysis was performed for $\alpha$-SMA relative to GAPDH. $\mathrm{B}$, The results are representative of four independent experiments after normalization to GAPDH. C, Immunofluorescence staining of $\alpha$-SMA (green) in cells $(400 \times)$. Nuclei are stained in blue with DAPI. D, The data represent the results of 6 independent experiments. *, $P<0.05, * *, P<0.01$ vs. Control; \#, $P<0.05$, $\# \#, P<0.01$ vs. NaHS; $\&, P<0.01$ vs. TGF- $\beta 1$.

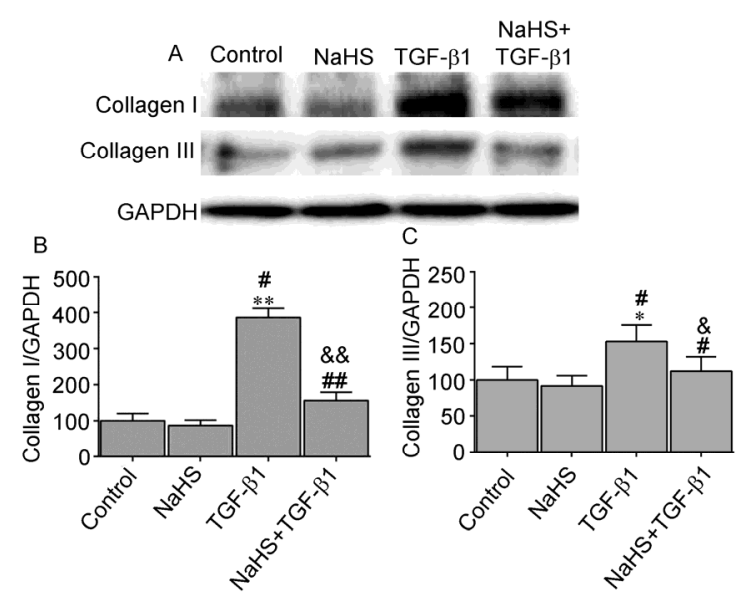

Figure $6 \quad \mathrm{H}_{2} \mathrm{~S}$ prevents TGF- $\beta 1$-induced Collagen I and Collagen III expression in HCF-av cells. A, Representative immunoblots of Collagen I and Collagen III expression in HCF-av cells in response to stimulation with TGF- $\beta 1\left(10 \mathrm{ng} \mathrm{mL}^{-1}\right)$ with or without NaHS $\left(100 \mu \mathrm{mol} \mathrm{L}^{-1}\right)$ for the indicated times. B and C, Densitometric analysis of cellular Collagen I (B) and Collagen III (C) normalized to GAPDH. *, $P<0.05$; **, $P<0.01$ vs. Control; \#, $P<0.05$; \#\#, $P<0.01$ vs. NaHS; $\&, P<0.05 ; \& \&, P<0.01$ vs. TGF- $\beta 1$ $(n=4)$.
$\mathrm{H}_{2} \mathrm{~S}$ strongly inhibited these effects.

Cell cycle checkpoints are major control mechanisms that maintain proper execution of cell cycle events. Following DNA damage, cells arrest at the transition from the $G_{1}$ to $S$ phase or from the $G_{2}$ to $M$ phase [19]. The proportion of cells that arrest at $G_{1}$ to $S$ or $G_{2}$ to $M$ phases depends on the cell type, growth conditions, and checkpoint controls operating in the cell [20], and cell arrest often leads to cell death. Deplancke and Gaskins [21] demonstrated that exposure to $\mathrm{H}_{2} \mathrm{~S}$ significantly increased the fraction of cells in the $S$ and $\mathrm{G}_{2} / \mathrm{M}$ cell cycle phases in the rat intestinal crypt IEC-18 cell line. In addition, they found that exposure to 0.05-1 mmol L ${ }^{-1}$ NaHS did not significantly alter the percentage of apoptotic cells. However, treatment with $5 \mathrm{mmol} \mathrm{L}^{-1}$ $\mathrm{NaHS}$ increased the apoptotic cell population. Yang et al. [22] demonstrated that $\mathrm{H}_{2} \mathrm{~S}$-induced apoptosis in human aorta smooth muscle cells (HASMCs) was concentration dependent, with significant apoptosis detected at concentrations of $200 \mu \mathrm{mol} \mathrm{L}{ }^{-1}$ and higher. In contrast, Baskar et al. [23] demonstrated that NaHS decreased the percentage 


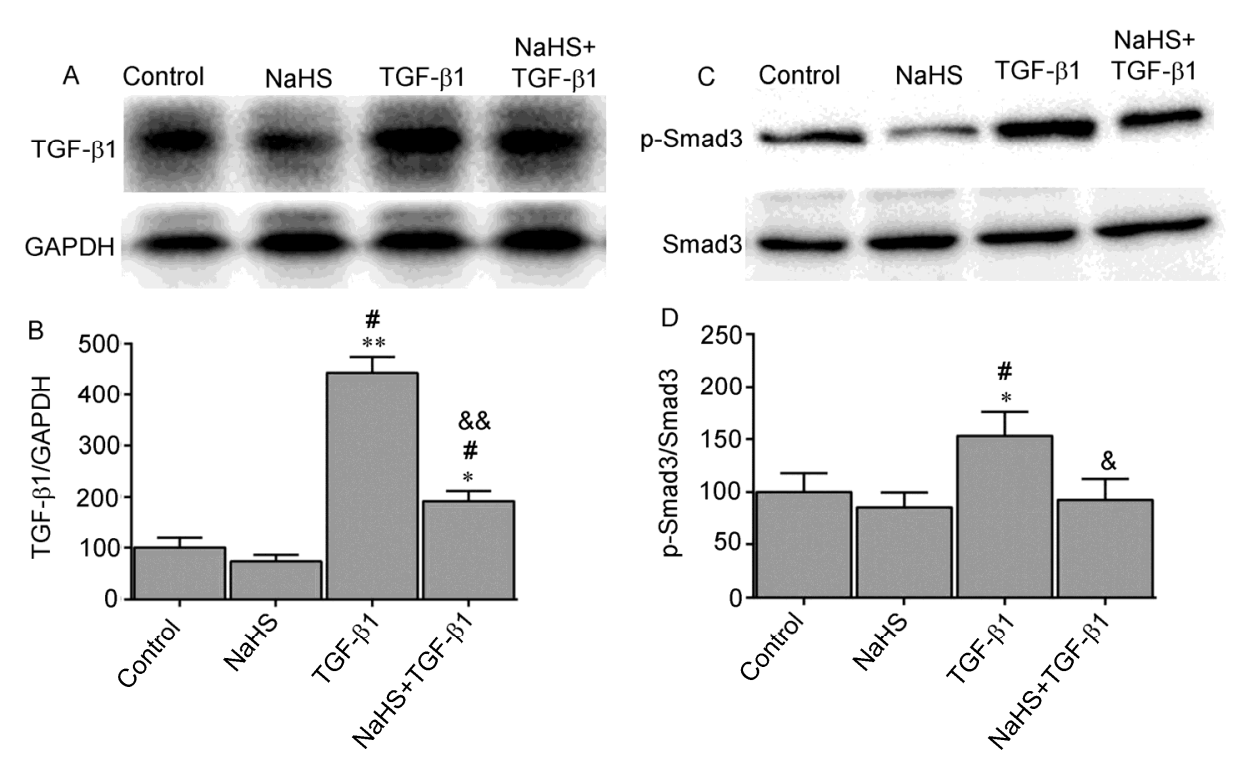

Figure $7 \quad \mathrm{H}_{2} \mathrm{~S}$ inhibits Smad3 activation evoked by TGF- $\beta 1$ in HCF-av cells. Western blot analysis was used to assess the expression of actived TGF- $\beta 1$ (A) and phospho-Smad3 (C) levels in cultured HCF-av cells exposed to TGF- $\beta 1\left(10 \mathrm{ng} \mathrm{mL}^{-1}\right)$ with or without NaHS treatment $\left(100 \mu \mathrm{mol} \mathrm{L}^{-1}\right)$. Densitometric analysis of cellular TGF- $\beta 1$ normalized to GAPDH (B) and p-Smad3 normalized to Smad3 (D). *, $P<0.05$; **, $P<0.01$ vs. Control; \#, $P<0.01$ vs. NaHS; $\&$, $P<0.05 ; \& \&, P<0.01$ vs. TGF- $\beta 1(n=4)$.

of normal human lung primary fibroblast (MRC-5) cells in $\mathrm{G}_{1}$ and $\mathrm{S}$ phases and induced a slightly higher incidence of cells in the $\mathrm{G}_{2} / \mathrm{M}$ phase. Furthermore, exposure to $50-75$ $\mu$ mol $\mathrm{L}^{-1}$ NaHS significantly increased the number of apoptotic cells. In the present study, we demonstrate that TGF- $\beta 1$ stimulation for $24 \mathrm{~h}$ significantly increased the number of HCF-av cells in the S phase, while NaHS abrogated this effect. Additionally, we did not observe a significant difference in the number of apoptotic cells (Annexin $\mathrm{V}^{+} \mathrm{PI}^{+}$) with TGF- $\beta 1$ and/or NaHS treatment. $\mathrm{H}_{2} \mathrm{~S}$ plays a different role in cell cycle distribution, which may vary depending on the cell type.

Myofibroblasts (mainly differentiated from fibroblasts) that express $\alpha$-SMA microfilaments and exhibit proliferative, migratory, and secretory properties are abundant in cardiac fibrosis. Therefore, preventing the differentiation of proliferating fibroblasts to myofibroblasts has been an attractive strategy for limiting cardiac fibrosis. Previous studies have shown that $\alpha$-SMA expression is regulated by TGF- $\beta 1$, a locally generated cytokine in heart failure that is downstream of many of the pro-fibrotic actions of other fibroblast growth factors, including Ang II, aldosterone, and norepinephrine [24]. TGF- $\beta 1$ is upregulated in failing human hearts and various experimental models of cardiac hypertrophy $[24,25]$. Functional blockade of TGF- $\beta 1$ prevents cardiac interstitial fibrosis induced by pressure overload in rats [26]. Previous studies have demonstrated that inhibition of TGF- $\beta 1$ function by anti-TGF- $\beta 1$ antibodies reduced myofibroblasts and reduced fibrosis. In addition, $\mathrm{H}_{2} \mathrm{~S}$ was found to inhibit TGF- $\beta 1$-induced transformation of MRC- 5 lung fibroblasts to myofibroblasts [27], and suppress endothelin-induced proliferation of rat aortic smooth muscle cells [28]. Moreover, a recent study showed that $\mathrm{H}_{2} \mathrm{~S}$ attenuated human atrial fibroblast proliferation via suppression of $\mathrm{K}^{+}$channel activity and moderated their differentiation to myofibroblasts [29]. In agreement with these recent findings, the present study showed that NaHS effectively inhibited TGF- $\beta 1$ expression and inhibited proliferation of HCF-av cells in response to TGF- $\beta 1$ stimulation. Furthermore, NaHS ameliorated fibroblast differentiation to myofibroblasts and significantly suppressed $\alpha$-SMA expression and their associated stress fibers.

Collagen proteins found in the normal myocardium include types I, III, IV, V, and VI. Fibrillar type I and III collagens are major components of the cardiac ECM. SDS-PAGE revealed that type I collagen, the most predominant $(>70 \%)$ in the normal myocardium of nonhuman primates and rodents, has the tensile strength of steel. Types III and $\mathrm{V}$ collagens account for up to $10 \%-15 \%$ and less than $5 \%$, respectively. In the heart, collagen is produced primarily by CFs. Previous studies have shown that type I and III collagen mRNAs in the infarcted myocardium are simultaneously increased with myofibroblast expression, suggesting that myofibroblasts are responsible for collagen synthesis in the repairing myocardium. In a previous study [30], we reported that recombinant human bone morphogenetic protein-2 (rhBMP-2) could attenuate pressure overload (transverse aortic constriction) induced collagen deposition, improve cardiac function, and reduce TGF- $\beta 1$-dependent activation of PKC- $\delta$ and Smad3. In the current study, con- 
sistent with changes in the number of myofibroblasts ( $\alpha$-SMA positive), we found that collagen I, collagen III, and $\mathrm{p}$-Smad3 activation were increased upon stimulation with TGF- $\beta 1$, however, administration of NaHS, attenuated collagen increase. In addition, TGF- $\beta 1$ can amplify its own expression in fibroblasts and myofibroblasts. Therefore, our results suggest that the TGF- $\beta 1 / \mathrm{Smad} 3$ signaling pathway plays an important role in myofibroblast differentiation during cardiac fibrosis.

In conclusion, the present study shows that NaHS inhibited TGF- $\beta 1$ secretion and TGF- $\beta 1$ induced Smad3 activation as well as prevented TGF- $\beta 1$-induced proliferation, migration, cell growth regulation, transformation to myofibroblasts, and collagen synthesis in an in vitro human cardiac fibroblasts-to-myofibroblasts assay. These effects provide insight into novel mechanisms with potential therapeutic implications for cardiac fibrosis of injured hearts.

The authors declare that they have no conflict of interest.

This work was supported by the State Key Program of National Natural Science of China (81230007).

1 Souders CA, Bowers SL, Baudino TA. Cardiac fibroblast: the renaissance cell. Circ Res, 2009, 105: 1164-1176

2 Weber KT, Sun Y, Bhattacharya SK, Ahokas RA, Gerling IC. Myofibroblast-mediated mechanisms of pathological remodelling of the heart. Nat Rev Cardiol, 2013, 10: 15-26

3 Liu X, Huang Q, Li F, Li CY. Enhancing the efficiency of direct reprogramming of human primary fibroblasts into dopaminergic neuron-like cells through p53 suppression. Sci China Life Sci, 2014, 57: $867-875$

4 Wang R. Hydrogen sulfide: the third gasotransmitter in biology and medicine. Antioxid Redox Signal, 2010, 12: 1061-1064

5 White BJ, Smith PA, Dunn WR. Hydrogen sulphide-mediated vasodilatation involves the release of neurotransmitters from sensory nerves in pressurized mesenteric small arteries isolated from rats. $\mathrm{Br} \mathrm{J}$ Pharmacol, 2013, 168: 785-793

6 Zhao W, Wang R. $\mathrm{H}_{2} \mathrm{~S}$-induced vasorelaxation and underlying cellular and molecular mechanisms. Am J Physiol Heart Circ Physiol, 2002, 283: H474-H480

7 Li W, Tang C, Jin H, Du J. Regulatory effects of sulfur dioxide on the development of atherosclerotic lesions and vascular hydrogen sulfide in atherosclerotic rats. Atherosclerosis, 2011, 215: 323-330

8 Xie X, Sun A, Zhu W, Huang Z, Hu X, Jia J, Zou Y, Ge J. Transplantation of mesenchymal stem cells preconditioned with hydrogen sulfide enhances repair of myocardial infarction in rats. Tohoku J Exp Med, 2012, 226: 29-36

9 Cucoranu I, Clempus R, Dikalova A, Phelan PJ, Ariyan S, Dikalov S, Sorescu D. NAD(P)H oxidase 4 mediates transforming growth factor-beta1-induced differentiation of cardiac fibroblasts into myofibroblasts. Circ Res, 2005, 97: 900-907

10 Ma Y, Halade GV, Zhang J, Ramirez TA, Levin D, Voorhees A, Jin YF, Han HC, Manicone AM, Lindsey ML. Matrix metalloproteinase-28 deletion exacerbates cardiac dysfunction and rupture after myocardial infarction in mice by inhibiting M2 macrophage activation. Circ Res, 2013, 112: 675-688
11 Gao Z, Sasaoka T, Fujimori T, Oya T, Ishii Y, Sabit H, Kawaguchi M, Kurotaki Y, Naito M, Wada T, Ishizawa S, Kobayashi M, Nabeshima Y, Sasahara M. Deletion of the PDGFR- $\beta$ gene affects key fibroblast functions important for wound healing. J Biol Chem, 2005, 280: 9375-9389

12 Zhang YE, Fu SZ, Li XQ, Chen P, Wang JL, Che J, Tang JM, Chen SY, Wang JN. PEP-1-SOD1 protects brain from ischemic insult fol-

lowing asphyxial cardiac arrest in rats. Resuscitation, 2011, 82: 1081-1086

13 Zhao G, Wang S, Wang Z, Sun A, Yang X, Qiu Z, Wu C, Zhang W, Li H, Zhang Y, Zhao J, Zou Y, Ge J. CXCR6 deficiency ameliorated myocardial ischemia/reperfusion injury by inhibiting infiltration of monocytes and IFN- $\gamma$-dependent autophagy. Int J Cardiol, 2013, 168: 853-862

14 Snider P, Standley KN, Wang J, Azhar M, Doetschman T, Conway SJ. Origin of cardiac fibroblasts and the role of periostin. Circ Res, 2009, 105: 934-947

15 Kiryu M, Niwano S, Niwano H, Kishihara J, Aoyama Y, Fukaya H, Masaki Y, Izumi T. Angiotensin II-mediated up-regulation of connective tissue growth factor promotes atrial tissue fibrosis in the canine atrial fibrillation model. Europace, 2012, 14: 1206-1214

16 Weber KT, Brilla CG. Pathological hypertrophy and cardiac interstitium. Fibrosis and renin-angiotensin-aldosterone system. Circulation, 1991, 83: 1849-1865

17 Scharenberg MA, Pippenger BE, Sack R, Zingg D, Ferralli J, Schenk $S$, Martin I, Chiquet-Ehrismann R. TGF- $\beta$-induced differentiation into myofibroblasts involves specific regulation of two MKL1 isoforms. J Cell Sci, 2014, 127: 1079-1091

18 Shinde AV, Frangogiannis NG. Fibroblasts in myocardial infarction: a role in inflammation and repair. J Mol Cell Cardiol, 2013,

19 Bunz F, Dutriaux A, Lengauer C, Waldman T, Zhou S, Brown JP, Sedivy JM, Kinzler KW, Vogelstein B. Requirement for p53 and p21 to sustain G2 arrest after DNA damage. Science, 1998, 282: 1497-1501

20 Hartwell LH, Kastan MB. Cell cycle control and cancer. Science, 1994, 266: 1821-1828

21 Deplancke B, Gaskins HR. Hydrogen sulfide induces serumindependent cell cycle entry in nontransformed rat intestinal epithelial cells. FASEB J, 2003, 17: 1310-1312

22 Yang G, Sun X, Wang R. Hydrogen sulfide-induced apoptosis of human aorta smooth muscle cells via the activation of mitogenactivated protein kinases and caspase-3. FASEB J, 2004, 18: 1782-1784

23 Baskar R, Li L, Moore PK. Hydrogen sulfide-induces DNA damage and changes in apoptotic gene expression in human lung fibroblast cells. FASEB J, 2007, 21: 247-255

24 Rosenkranz S. TGF-beta1 and angiotensin networking in cardiac remodeling. Cardiovasc Res, 2004, 63: 423-432

25 Lan Y, Yang X. The role of smad signaling in vascular and hematopoietic development revealed by studies using genetic mouse models. Sci China Life Sci, 2010, 53: 485-489

26 Kuwahara F, Kai H, Tokuda K, Kai M, Takeshita A, Egashira K, Imaizumi T. Transforming growth factor-beta function blocking prevents myocardial fibrosis and diastolic dysfunction in pressureoverloaded rats. Circulation, 2002, 106: 130-135

27 Fang LP, Lin Q, Tang CS, Liu XM. Hydrogen sulfide suppresses migration, proliferation and myofibroblast transdifferentiation of human lung fibroblasts. Pulm Pharmacol Ther, 2009, 22: 554-561

28 Du J, Hui Y, Cheung Y, Bin G, Jiang H, Chen X, Tang C. The possible role of hydrogen sulfide as a smooth muscle cell proliferation inhibitor in rat cultured cells. Heart Vessels, 2004, 19: 75-80

29 Sheng J, Shim W, Wei H, Lim SY, Liew R, Lim TS, Ong BH, Chua YL, Wong P. Hydrogen sulphide suppresses human atrial fibroblast 
proliferation and transformation to myofibroblasts. J Cell Mol Med, 2013, 17: 1345-1354

30 Wang S, Sun A, Li L, Zhao G, Jia J, Wang K, Ge J, Zou Y.
Up-regulation of BMP-2 antagonizes TGF-beta1/ROCK-enhanced cardiac fibrotic signalling through activation of Smurf1/Smad6 complex. J Cell Mol Med, 2012, 16: 2301-2310

Open Access This article is distributed under the terms of the Creative Commons Attribution License which permits any use, distribution, and reproduction in any medium, provided the original author(s) and source are credited. 